\title{
Effective weld lengths of RHS overlapped K connections with the transverse gusset plates
}

\author{
P. Milewski \& M. Broniewicz \\ Bialystok University of Technology, Biatystok, Poland
}

\begin{abstract}
European recommendations for rectangular hollow section (RHS) connection design requires that welds between truss bracing members and chords should have the same resistance as the yield capacity of the member. In the case of weld design based on the actual forces acting in the elements, the designer can use a smaller size of welds, meeting the requirements of the connection deformation and rotation capacity. For overlapped $\mathrm{K}$ and $\mathrm{N}$ connections, limited experimental research (Davies \& Packer (1982)), on 50\% overlaps connections have shown that entire overlapping bracing member contact perimeter can be considered as effective. However, no studies of overlapped joints have been carried out so far, with values of overlap from $25 \%$ to $50 \%$ and from $50 \%$ to $100 \%$ being used for overlapped $\mathrm{K}$ connections with transverse gusset plates. The finite element analysis (FEM) results presented in the article show that the stress distribution in the welds connecting the braces with the chord in $\mathrm{K}$ overlapped joints with the transverse gusset plate is varied and depends both on the value of the angle of the brace concerning the chord, the overlap ratio and the brace to chord width ratio. For inclination angles of braces to the chord of $54^{\circ}$ and $60^{\circ}$, the outer transverse welds are considered to be only partially effective, with the degree of effectiveness depending on the overlap ratio and the wall slenderness values.
\end{abstract}

\section{INTRODUCTION}

Hollow sections have strength, stability, operational and aesthetic advantages, and with a large gradation of the dimensions of sections and their thicknesses, they are suitable for economical design. The traditional shaping of joints, especially of circular hollow sections, leads to low-tech solutions requiring a lot of shop labour, making components too expensive to compete economically with hot-rolled, open sections. Construction difficulties and the relatively high price of hollow sections (particularly rectangular ones) made it necessary to develop modern design solutions.

Hollow sections can be reduced to a few basic shapes, suitable for both round and rectangular (or square) sections, convenient for semi-automatic control of production processes in a steel structure factory. These solutions are, typically, devoid of additional gusset plates or ribs and are cost-effective, in terms of labour consumption, but they require designers to consider the flexural stiffness of the connections between hollow sections. Due to the similarity of hollow section joints to letters, they are designated as K, N, KT, T, Y and X joints.

\section{DESIGN OF WELDS IN K-TYPE JOINTS}

The design procedure for K-type joints with mutually overlapping braces made of closed rectangular sections is included in EN 1993-1-8 (2006) and discussed in the publications Brodka \&

DOI: $10.1201 / 9781003132134-42$ 
Broniewicz (2001), Brodka \& Broniewicz (2004), Brodka \& Broniewicz (2016), Dutta (1999), and Packer et al. (2009). However, the accepted standards, such as those developed by the IIW (1999) or the ISO standard (prepared on their basis) BS ISO 14346 (2011), do not include recommendations regarding issues related to the design of welds between the joined elements. Also, the European standard (EN 1993-1-8 2006) for the design and calculation of structural steel joints, sets out very general recommendations for the assessment of the resistance of members' joints made of hollow sections. Design guidelines IIW (1999), also included in the ISO standard BS ISO 14346 (2011), present a method of checking the shear strength of fillet welds in the plane of contact of braces with the chord in K-type joints with partial or full overlaps using the formulas:

- when $\lambda_{o v, \lim }<\lambda_{o v}<100 \%$ then:

$$
N_{i} \cos \theta_{i}+N_{j} \cos \theta_{j} \leq 0,58 f_{u i} \frac{2 h_{i, r e d}+b_{i . e f f}}{\sin \theta_{i}} t_{i}+0,58 f_{u j} \frac{2 h_{j}+c_{s} b_{j . e f f}}{\sin \theta_{j}} t_{j}
$$

- when $\lambda_{o v, \lim }=100 \%$ then:

$$
N_{i} \cos \theta_{i}+N_{j} \cos \theta_{j} \leq 0,58 f_{u i} \frac{2 h_{i, r e d}+b_{j}}{\sin \theta_{i}} t_{i}
$$

where $N_{i}=$ design axial load in the overlapping brace; $N_{j}=$ design axial load in the overlapped brace; $\theta_{i}, \theta_{j}=$ respectively angles of overlapping and overlapped braces in relation to the chord; $f_{u i}, f_{u j}=$ tensile strength of overlapping and overlapped braces, respectively, provided that $f_{u i} \leq f_{u 0}$ and $f_{u j} \leq f_{u 0}$ ( $f_{u 0}$ is the yield strength of the steel used in the chord); $h_{i, \text { red }}=$ $\left(100-\lambda_{o v}\right) h_{i} / 100 ; b_{i}, h_{i}=$ the width and the height of a cross section of the overlapping brace, respectively; $t_{i}=$ wall thickness of the overlapping brace; $t_{j}=$ wall thickness of the overlapped brace; $t_{0}=$ wall thickness of the chord; $b_{0}=$ width of the chord section and $f_{y 0}, f_{y i}, f_{y j}=$ yield strength of the chord, overlapping and overlapped braces, respectively;

$$
\begin{array}{ll}
b_{i . e f f}=\frac{10}{b_{0} / t_{0}} \frac{t_{0} f_{y 0}}{t_{i} f_{y i}} b_{i} ; & b_{i . e f f} \leq b_{i} \\
b_{j . e f f}=\frac{10}{b_{0} / t_{0}} \frac{t_{0} f_{y 0}}{t_{j} f_{y j}} b_{j} ; & b_{j . e f f} \leq b_{j}
\end{array}
$$

The hidden seam of the brace with the chord can be welded or left without welding. This is expressed by the value $\lambda_{o v, \text { lim }}$ and coefficient $c_{s}$. It is assumed that:

- $c_{s}=1$ and $\lambda_{o v, \text { lim }}=60 \%$ if the hidden seam of overlapped brace is not welded, - $c_{s}=2$ and $\lambda_{o v, \lim }=80 \%$ if the hidden seam of overlapped brace is welded.

In the case of RHS joints, due to the variable stiffness of the thin-walled chord face, which de-creases from the wall edges towards the centre, the force transmitted by the transverse welds is not evenly distributed. The greatest load is transferred through the weld areas closest to the side walls, while the central region may not contribute to the load transmission at all. This can be taken into account in the design of welds using the method of determining their effective lengths. The effective length is the reduced length of the weld, reflecting the way it is strained. Failure to take into account the uneven distribution of stresses in the weld in the design may cause the weld in the area of the side walls to crack, starting at the ends.

Longitudinal welds parallel to the axis of a square or rectangular HSS can be assumed to be fully effective.

This effective length of transverse welds and transverse elements was introduced based on ex-perimental studies conducted by Rolloos (1969), Wardenier et al. (1981) and Davies \& Packer (1982). 


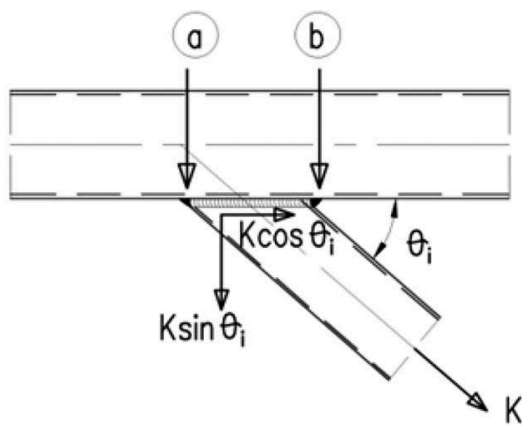

Figure 1. RHS Y-connection under branch axial tension.

From these tests, it was found that the outer transverse weld in a $\mathrm{K}$ gap connection (weld "b" in Figure 1) could only be considered effective in carrying the load when the angle between the brace and the chord $\theta_{i} \leq 50^{\circ}$. It follows that the effective lengths for RHS bracing member welds in gap $\mathrm{K}$ connections can be written using the equations:

$$
L_{i . e f f}=\left(\frac{2 h_{i}}{\sin \theta_{i}}\right)+2 b_{i} ; \quad \text { when } \quad \theta_{i} \leq 50^{\circ} ; \quad L_{i . e f f}=\left(\frac{2 h_{i}}{\sin \theta_{i}}\right)+b_{i} ; \quad \text { when } \quad \theta_{i} \geq 60^{\circ}
$$

For $50^{\circ}<\theta_{i}<60^{\circ}$ a linear interpolation is recommended.

\section{CALCULATION PROCEDURE OF EFFECTIVE WELD LENGTHS IN K-TYPE JOINTS WITH TRANSVERSE GUSSET PLATE}

A procedure for the approximate evaluation of resistance of welded $\mathrm{T}, \mathrm{Y}, \mathrm{X}, \mathrm{K}$ and $\mathrm{N}$ gap joints was developed in Brodka \& Broniewicz (2003) and in Brodka \& Broniewicz (2004). The procedure was extended to joints made of circular hollow sections.

In subsequent publications (Brodka \& Broniewicz 2013) these authors suggest an approximate assessment of the resistance of the welded connection in the overlapped $\mathrm{K}$ type joints, made of rectangular hollow sections (square).

The principles for designing truss joints made of rectangular hollow sections with a transverse gusset plate between the braces are not included in the provisions of ISO (2011) or IIW (1999). This is the result of an increase in required performance due to cutting and welding processes. Therefore, there is a lack of basic information about the resistance and the shaping of such joints in IIW (1999), AISC (2016) and AWS (2010) These joints are simple and necessary in some designs. Joints with a transverse gusset plate are useful when:

a) support joints are specifically designed to slightly overlap,

b) groove welds between brace members are omitted,

c) there is a small overlap of the brace members which is not recommended by EN 1993-1-8

(2006) and, despite their occurrence, requires strength assessment.

The basic shapes of the joints with the reinforcing gusset plates between the braces are shown in Figure 2, in the case of trusses made of square hollow sections. In relatively rare cases, rectangular hollow sections are also used, but the geometry of the joints remains the same. Mostly, the braces have the same width and height. Depending on the kind of truss used, the angles of inclination of the braces are different. Similarly, the joints made of circular hollow sections are shaped sometimes with minor changes. 
a)

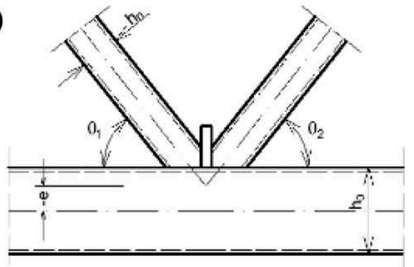

b)

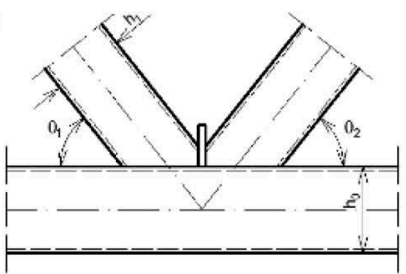

c)

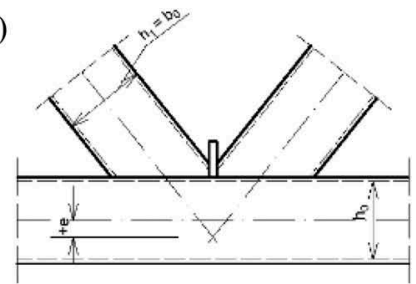

Figure 2. Intermediate joint made of rectangular hollow sections with a reinforcing plate: a) $-e<0,5 h_{0}$, b) $e=0$, c) $e \leq 0.25 h_{0}$.
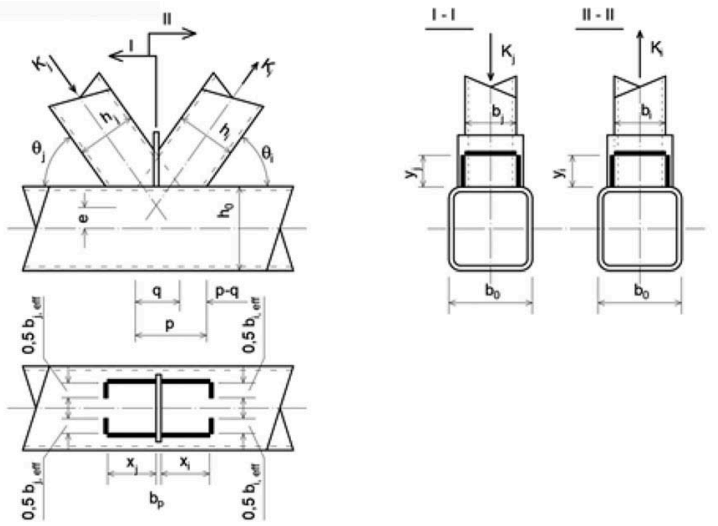

Figure 3. Weld layout in SHS overlap joint with transverse gusset plate.

The method of evaluation of the resistance of the welds in overlap joints with transverse gusset plates, using the formulas given in EN 1993-1-8, was presented by Brodka and Broniewicz (2015). To determine the resistance of the joints, the layout of the welds presented in Figure 3 are considered. In this figure, the dimensions of all of the welds in the spliced braces, with the chord and gusset plate, are indicated.

The lengths of these welds are determined as follows (Figure 4):

$$
\begin{gathered}
l_{1}=x_{j}-1,4 a_{w p}=\left(h_{j} / \sin \theta_{j}-0,5 q-0,5 t_{p}\right)-1,4 a_{w p} ; \quad l_{2}=b_{j . e f f} \\
l_{3}=y_{j}-1,4 a_{w p}=0,5\left(q+t_{p}\right) \tan \theta_{j}-1,4 a_{w p} ; \quad l_{4}=b_{j}
\end{gathered}
$$

\section{EVALUATION OF ANALYTICAL PROCEDURE AND FEM ANALYSIS ON RHS OVERLAP K JOINT WELDS WITH TRANSVERSE GUSSET PLATE}

\subsection{Stress distribution in welds based on the numerical FEM analysis}

FEM numerical tests were carried out for K-type joints with transverse plates made of SHS, at different angles of brace inclination $\theta_{i}$ and different degrees of overlap ratio $\lambda_{o v}$. To obtain different angles of brace inclination, a lattice girder with a span of $12.0 \mathrm{~m}$ was varied, in terms of height, i.e. $1.70 \mathrm{~m}, 1.40 \mathrm{~m}$ and $1.10 \mathrm{~m}$. Corresponding angles of brace inclination to the bottom chord were $60^{\circ}, 54^{\circ}$, and $48^{\circ}$. The truss was loaded with concentrated forces from the standard 


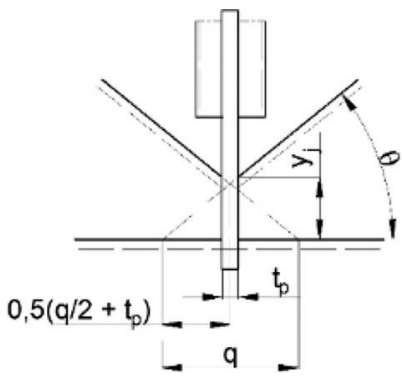

Figure 4. Height of the vertical weld of the plate.

loads (dead, snow, wind loads) in the joints of the top chord. Square hollow sections of SHS $(120 \times 4 \mathrm{~mm})$ were assumed for the sections of the top and bottom chord, while the braces were SHS of $60 \times 3 \mathrm{~mm}$. The ratio of overall brace width to chord width for SHS was constant and equal, $\beta=0,5$. The thickness of the transverse gusset plate was taken to be $5 \mathrm{~mm}$.

The values of stress in the welds decrease with increasing distance from the centre of the joint. This is due to greater stiffness of the joint between the braces $\left(b_{i} / b_{j}=1,0\right)$ than between the brace and the chord $\left(\beta=b_{i} / b_{0}=0,5\right)$ (Figure 5). As the overlap parameter increases, the stress reduction becomes less pronounced and is usually accompanied by an increase in the average stress in the welds.

The stresses in the internal transverse welds connecting the braces with the plate show a high value along the entire length of the weld. This is due to the high flexural stiffness of the joint area, re-sulting from the high value of the coefficient $\beta$. The stresses in the external transverse welds connecting the braces with the chord, decreased almost to zero, which is related to the high value of the chord wall flexibility $\left(\beta=0,5, \lambda=b_{0} / t_{0}=30\right)$. In the longitudinal welds, the stresses were relatively evenly distributed, with a slight decrease in the value away from the centre of the joint. of the joint $\lambda_{o v}=30 \%$.

The high value of stresses in the transverse weld between the braces and the gusset plate is mainly due to the stiffening of this joint zone by the transverse plate, which increases the stiffness connections and also the effective length of the weld.
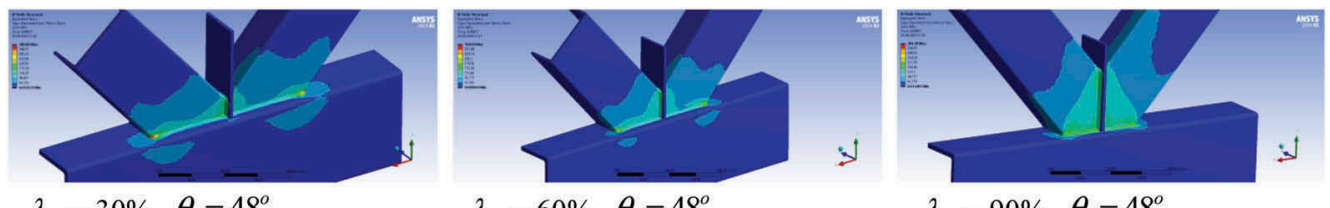

$\lambda_{o v}=30 \% \quad \theta_{1}=48^{\circ}$

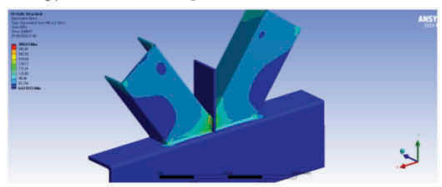

$\lambda_{o v}=60 \% \quad \theta_{1}=48^{\circ}$

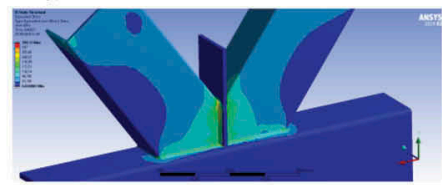

$$
\lambda_{o v}=90 \% \quad \theta_{1}=48^{\circ}
$$

$\lambda_{o v}=30 \% \quad \theta_{1}=54^{\circ}$

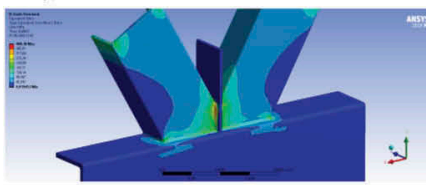

$$
\lambda_{o v}=60 \% \quad \theta_{1}=54^{\circ}
$$

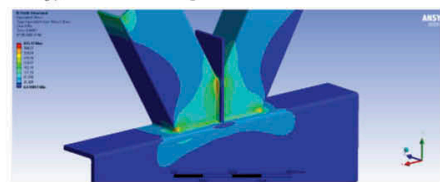

$\lambda_{o v}=30 \% \quad \theta_{1}=60^{\circ}$ $\lambda_{o v}=60 \% \quad \theta_{1}=60^{\circ}$

Figure 5. Distribution of stresses around braces. 


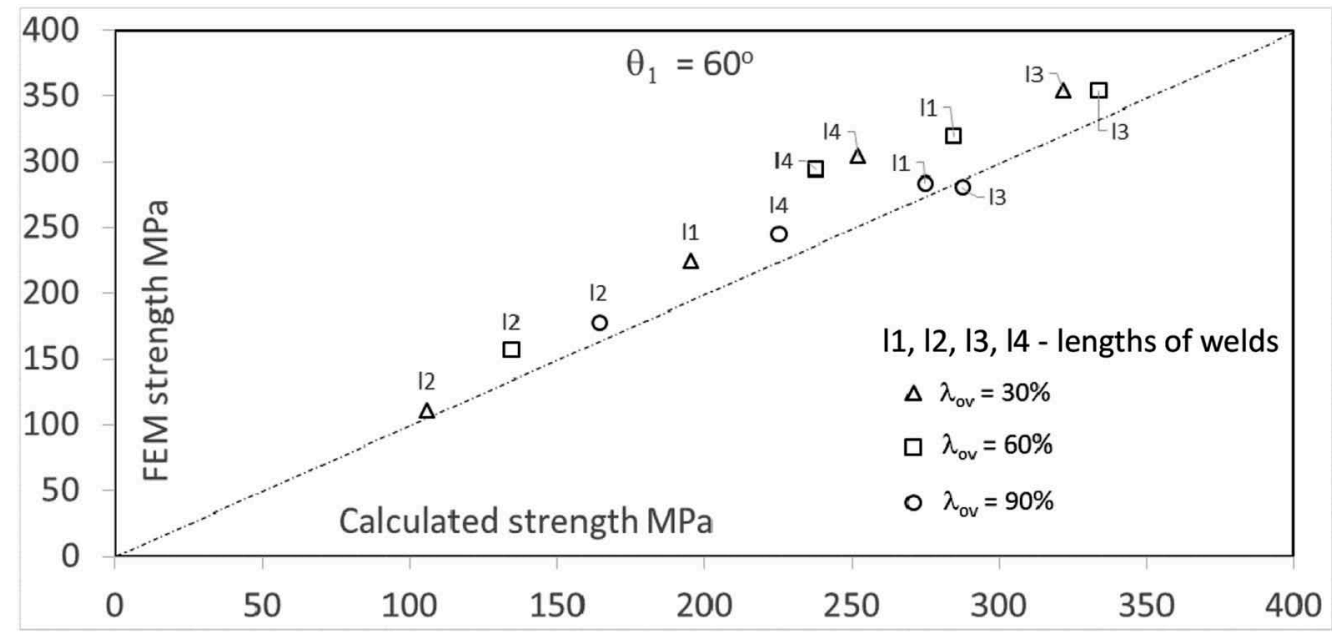

Figure 6. Correlation of FEM analysis with the analytical results for $\theta_{1}=60^{\circ}$.

The stress distribution in the welds around the joined elements shows that the longitudinal welds can be considered to be fully effective, with overlap coefficients $\lambda_{o v}=60 \%$ and $90 \%$. In the case of $\lambda_{o v}=30 \%$, the stress distribution in longitudinal welds is more non-uniform.

The outer transverse welds are only partially effective and become less effective as $\lambda_{o v}$ and $\beta$ decreases.

\subsection{Correlation of analytical results with the numerical FEM analysis}

The analytical procedure proposed by Brodka and Broniewicz (2015) was used to calculate the nominal strengths of the welded connections analysed. The calculated strength of each welded connection was determined by the summation of the individual weld element strengths along the four walls around the braces. The values were calculated analytically and compared with the values obtained from the FEM numerical analysis.

The correlation of FEM analysis with the analytical results is presented in Figure 6.

\section{CONCLUSIONS}

As part of this research, nine different RHS overlap K connections with transverse gusset plate joints were analysed, using the FEM computerised analysis method. Stress distribution, according to the finite element analysis for defined $\lambda_{o v}$ and $\theta$ parameters, is presented in Figure 5.

The analysis shows that all longitudinal welds are effective in stress transfer, with their distribution depending on the distance from the centre of the joint. The outer transverse welds, on the other hand, are not always effective in stress transmission. Their effectiveness depends on the degree of member overlap $\lambda_{o v}$ and the angle of the diagonals $\theta$. In the case of large angles of the braces to the chord $\left(60^{\circ}\right)$, their effectiveness in stress transfer increases. Also, their effec-tiveness decreases as the overlap parameter of lambda $\lambda_{o v}$ decreases. This is due to the greater rigidity of the central part of the joint.

The analytical method of calculating the weld resistance in RHS K-type joints with a transverse gusset plate, taking into account the effective weld lengths, allows for the rational design of welded joints made of hollow sections. It takes into account the actual forces that occur, which results in welds of smaller thicknesses, and this ensures the aesthetics and costeffectiveness of the structural solution. Comparison of the stress values occurring in individual welds obtained in an analytical way, with those using the FEM numerical method, indicates 
that the analytical method developed by Brodka and Broniewicz (2007) determines the actual weld stress level very well.

A further experimental study to determine the effective weld length in RHS K-type joints with a transverse gusset plate, is being carried out at the Bialystok University of Technology. Key pa-rameters, such as branch-to-chord angles $\theta=48^{\circ}, 54^{\circ}, 60^{\circ}$ and member overlap $\lambda_{o v}=$ $30 \%, 60 \%$ and $90 \%$, are being investigated. During the tests, the uneven stress distribution in the welds will be measured with the use of strain gauges, which will allow the determination of the actual stress distribution in the welds for different configurations of elements in the joints and will allow for safe design of K-type RHS joints with transverse gusset plates.

\section{ACKNOWLEDGEMENT}

This research was funded by grants numbers: WI/WB-IIL/B/2020); WZ/WBIIL/4/2020.

\section{REFERENCES}

ANSI/AISC 360. 2016. An American National Standard, AISC Specification for Structural Steel Buildings.

AWS D1.1/D1.1M:2010 Structural Welding Code—Steel. An American National Standard.

Brodka, J. \& Broniewicz, M. 2001. Steel structures made of hollow sections. Warsaw. Arkady. (in Polish)

Brodka, J. \& Broniewicz, M. 2003. Calculation of welded connections of truss joints from RHS. Warsaw: Steel structures. (in Polish)

Brodka, J. \& Broniewicz, M. 2004. Assessment of the load-bearing capacity of joints with welds laid at rounded corners of cold formed profiles. Warsaw: Steel structures. (in Polish)

Brodka, J. \& Broniewicz, M. 2013. Calculation of welding trusses overlap joints made of rectangular hollow sections. Warsaw: Archives of Civil Engineering.

Brodka, J. \& Broniewicz, M. 2015 Design Of Hollow Section Overlap Joints With The Reinforcing Rib Plate. Welded Connection Resistance. Warsaw: Archives of Civil Engineering.

Brodka, J. \& Broniewicz, M. 2016. Steel structures made of structural hollow sections. Part. 1. Warsaw: PWN. (in Polish)

BS ISO 14346, 2011. Welding - Static design procedure for hollow section joints.

Rolloos, A. (1969), "The Effective Weld Length of Beam to Column Connections without Stiffening Plates," Stevin Report 6-69-7-HL, Delft University of Technology, Delft, The Netherlands.

EN 1993-1-8:2006: Eurocode 3: Design of steel structures - Part 1-8: Design of joints.

Davies, G. and Packer, J.A. (1982), "Predicting the Strength of Branch Plate-RHS Connections for Punching Shear," Canadian Journal of Civil Engineering, Vol. 9, pp. 458-467.)

Dutta, D. 1999. Hohlprofil - Konstruktionen. Berlin: Ernst und Sohn. A Willey Company.

Packer, J.A. Wardenier, J. Zhao, X.L. van der Vegte, G.J. \& Kurobane Y. 2009. Design guide for rectangular hollow section (RHS) joints under predominantly static loading. LSS Verlag. CIDECT.

IIW 1999. Static design procedure for welded hollow section joints. Recommendations. 3rd Edition. International Institute of Welding. Commision XV. IIW Doc. XV-1329-09.

Wardenier, J., Davies, G. and Stolle, P. (1981), "The Effective Width of Branch Plate to RHS Chord Connections in Cross Joints," Stevin Report 6-81-6, Delft University of Technology, Delft, The Netherlands. 